\title{
Penile Sarcoma
}

National Cancer Institute

\section{Source}

National Cancer Institute. Penile Sarcoma. NCI Thesaurus. Code C7730.

A malignant mesenchymal neoplasm that arises from the penis. Representative examples include Kaposi sarcoma, leiomyosarcoma, and angiosarcoma. 